\title{
Early Outcome of Surgery in Pediatric Head Injury: Experience From a Tertiary Care Center in Eastern Nepal
}

\author{
Babita Khanal', Prakash Kafle², Sandip K Singh1, Sunil K Yadav', Bishomber Neupane², Ipsa \\ Shakya², Dipak K Yadav² \\ 'Department of Pediatric Medicine, ${ }^{2}$ Department of Neurosurgery, Nobel Medical College and Teaching Hospital, \\ Biratnagar, Nepal
}

\section{Corresponding author:}

Prakash Kafle, MS, MCh

Department of Neurosurgery, Nobel Medical College and Teaching Hospital, Biratnagar, Nepal

Email:prakashkaflee@gmail.com

Submitted : Jun 22, 2020

Accepted : Aug 4, 2020

\begin{abstract}
\section{Introduction}

Head injuries among the pediatric age group remain an unwelcomed source of morbidity and mortality resulting from falls, motor vehicle accidents, assaults, and child abuse. Early identification and management of traumatic brain injury (TBI) are crucial in halting the progress of the primary insult and preventing or reducing secondary brain injury. The present study aims to investigate the major cause of pediatric TBI and analyze the early outcome and serve as a reference study from a tertiary care center in eastern Nepal.

\section{Methods}

This is a prospective cohort study conducted in the Department of Pediatric Medicine and Neurosurgery from February 2018 to January 2020. All the pediatric head injury cases that were managed surgically in the center were included in the study. Presenting Glasgow coma scale (GCS) was correlated with the Glasgow outcome scale (GOS).

\section{Results}

The study population comprised of 65 patients fulfilling the study inclusion criteria. The mean age of the study population was $10.86 \pm 4.72$ years, fall was the commonest mode of injury (52.3\%), $50.8 \%$ had mild $\mathrm{TBI}, 43.1 \%$ had moderate TBI and $6.2 \%$ had severe TBI. Depressed skull fracture with underlying extradural hematoma (EDH) or contusion was the commonest pathological diagnosis seen in $30.8 \%$ (20) cases. The mean duration of hospital stay was 2.6 days. The presenting GCS correlated well with the outcome.
\end{abstract}

\section{Conclusion}

This study concluded that the timely management of pediatric TBI can prevent grave prognosis and the patients presenting GCS and the pupillary reaction has strong correlation with the outcome.

Keywords: Head injury, Glasgow outcome score, pediatric, surgery 


\section{INTRODUCTION}

$\longrightarrow$ raumatic brain injury (TBI) is defined as damage to the brain resulting from an external mechanical force, including accelerating, decelerating, and rotating forces. ${ }^{1}$ Despite the progress made in injury prevention, pediatric trauma remains significant. ${ }^{2}$ TBI has been classified as mild (Glasgow Coma Scale [GCS] 13-15), moderate (GCS 9-12), and severe (GCS 3-8). Responsiveness is assessed with the Alert, Verbal, Pain, Unresponsive system, and with the GCS 3 and its modified pediatric GCS. ${ }^{4}$ A review examining the worldwide incidence rate of pediatric Traumatic Brain Injury (TBI) revealed variations by country ranging from 47 to 280 per 100,000 children. Rates of hospital admissions vary widely. ${ }^{5}$ In the developed countries most common cause of TBI includes fall injury preceding motor vehicle accidents. Child abuse remains the major cause of head injury among under 2 years of age. Infants and young children are more prone to abuse by adults looking after them, which may lead to head injuries. ${ }^{6}$

In Nepal, the pediatric population is about $34.91 \%$. $^{7}$ Children are vulnerable to accidents at home, school, playground apart from motor vehicle accidents and falls. Possible morbidity includes potential neurological devastation, years of loss of productivity, low quality of life, dependence, and death. ${ }^{8}$ After the immediate visits to health posts and secondary care centers, the case reaches late to tertiary care centers with different mechanisms of injury. The initial and instant assessment of the case with necessary investigations especially computed tomography (CT) scan determines the severity of $\mathrm{TBI}$ and the need for emergency operative intervention. ${ }^{9}$ Patient age, clinical indices indicating the severity of brain injury and evidence of raised intracranial pressure and the results of imaging studies, particularly CT scan, disclose the nature of brain injury. The nature of brain injury and its effects on intracranial dynamics remains the important prognostic indicator, which accounts to make clinical decisions. ${ }^{10}$

As in other developing countries, pediatric TBI is a subject of concern in our world. This study primarily aims to correlate the pupillary reaction and the short term outcome in surgically managed pediatric TBI and also to illuminate the various modes of injury, severity, management at the tertiary care center, complications, and outcomes in TBI in the pediatric population. This would help to take appropriate measures to manage pediatric TBI in the developing world.

\section{METHODS}

This is a prospective cohort study carried out in the department of neurosurgery and pediatric medicine at Nobel Medical College teaching hospital (NMCTH), a tertiary care center in the Eastern part of Nepal where all types of pediatric neurosurgical problems are addressed. The study was conducted from February 2018 to January 2020. This study was conducted under the permission of Institutional Review Board Nobel Medical College and Teaching Hospital and the ethical clearance was granted by the same. All the pediatric head injury cases, which were primarily managed surgically in our center, were included in the study. Those operated at other centers or referred for further management and pediatric TBI with other associated injuries demanding surgical intervention were excluded from the study. The data were collected from the patient's observation chart and files, then electronically transferred, and analyzed using the IBM SPSS version 20 software. Categorical variables were expressed in percentage and numerical variables were expressed in mean. The correlation was calculated using the Spearman Rank correlation test with the statistical significance at p-value $<0.05$.

\section{RESULTS}

During the study period, a total of 70 pediatric patients with the diagnosis of TBI underwent surgical management. Among them, 5 were lost in the follow up. So only 65 cases were analyzed in the current study. The mean age of the study population was 10.86 years $(S D \pm 4.72$ ) ranging from 1 year to 16 years. In the present study $43(66.15 \%)$ were male and $22(33.85 \%)$ were female with a male: female ratio of $1.9: 1$. The study population demographics are shown in Table 1.

Out of total patients $51(78.5 \%)$ presented with both reactive pupil, 13 (20\%) presented with one reactive and one non-reactive pupil, and 1 (1.5\%) presented with both non-reactive pupil (Table 2 ). The correlation between pupils' reaction on admission and the GOS score on discharge, 4 weeks follow up and 12 weeks follow up was analyzed and the correlation was statistically significant ( $p$-value $<0.05)$. The Spearman correlation coefficient for GOS was $0.413,0.481$, and 0.502 at discharge $(p=0.001), 4$ weeks $(p<0.001)$, and 12 weeks $(p<0.001)$ respectively. There was a strong correlation between the pupils' reactions and GOS. The pupils' reaction and the GOS at different periods are as described in the Table 2.

Out of 65 patients, 63 (96.9\%) most of the lesions were supratentorial in the location which was treated by craniotomy and $2(3.1 \%)$ were infratentorial where posterior fossa craniectomy and extradural hematoma evacuation was done. Of the 27 depressed skull fracture, 3 cases had large underlying contusion so the elevation of depressed skull fracture was enough only in 24 cases (36.91\%). Other surgical modalities of treatment were 
Table 1. Summary of different characteristics of the study population $(n=65)$

\begin{tabular}{|c|c|c|}
\hline Variables & Number & Percentage \\
\hline \multicolumn{3}{|l|}{ Age } \\
\hline $0-<2$ Years & 1 & 1.5 \\
\hline $2-<5$ Years & 15 & 23.1 \\
\hline $5-<10$ Years & 9 & 13.9 \\
\hline $10-16$ years & 40 & 61.5 \\
\hline \multicolumn{3}{|l|}{ Mode of injury } \\
\hline Fall injury & 34 & 52.3 \\
\hline RTA & 28 & 43.1 \\
\hline Physical Assault & 2 & 3.1 \\
\hline Wind Mill injury & 1 & 1.5 \\
\hline \multicolumn{3}{|l|}{ Presenting Features } \\
\hline Vomiting & 28 & 43.1 \\
\hline Loss of Consciousness & 18 & 27.6 \\
\hline Headache & 9 & 13.9 \\
\hline ENT Bleed & 5 & 7.7 \\
\hline Focal Deficits & 3 & 4.61 \\
\hline Seizure & 2 & 3.1 \\
\hline \multicolumn{3}{|l|}{ Grading of Injury } \\
\hline Mild (GCS 13-15) & 33 & 50.7 \\
\hline Moderate (GCS 9-12) & 28 & 43.1 \\
\hline Severe $(\mathrm{GCS} \leq 8)$ & 4 & 6.2 \\
\hline \multicolumn{3}{|l|}{ Diagnosis } \\
\hline \multicolumn{3}{|l|}{ Depressed Skull Fracture } \\
\hline With Contusion & 27 & 41.5 \\
\hline $\mathrm{EDH}$ & 17 & 26.1 \\
\hline $\mathrm{SDH}$ & 11 & 17 \\
\hline Contusion Only & 5 & 7.7 \\
\hline Degloved Scalp & 5 & 7.7 \\
\hline \multicolumn{3}{|l|}{ Associated Injuries } \\
\hline Maxillofacial & 4 & 6.2 \\
\hline Orthopedic & 3 & 4.6 \\
\hline BAT & 3 & 4.6 \\
\hline Spine & 2 & 3.1 \\
\hline Multiple & 2 & 3.1 \\
\hline Thoracic & 1 & 1.5 \\
\hline \multicolumn{3}{|l|}{$\begin{array}{l}\text { Treatment Modalities } \\
\text { Elevation of Depressed }\end{array}$} \\
\hline Skull fracture & 24 & 36.9 \\
\hline EDH Evacuation & 17 & 26.1 \\
\hline SDH Evacuation & 11 & 17 \\
\hline Contusectomy & 8 & 12.3 \\
\hline $\begin{array}{l}\text { Debridement of degloved } \\
\text { scalp }\end{array}$ & 5 & 7.7 \\
\hline \multicolumn{3}{|l|}{ Hospital Stay } \\
\hline Less than 7 days & 34 & 52.3 \\
\hline 8-10 days & 21 & 32.4 \\
\hline More than 10 days & 10 & 15.4 \\
\hline
\end{tabular}

EDH evacuation in $17(26.1 \%), \mathrm{SDH}$ evacuation in $11(17 \%)$, and $8(12.3 \%)$ underwent contusectomy and debridement of the degloved scalp in $5(7.69 \%)$ cases (Table 1). Among 57(87.7\%) patients there

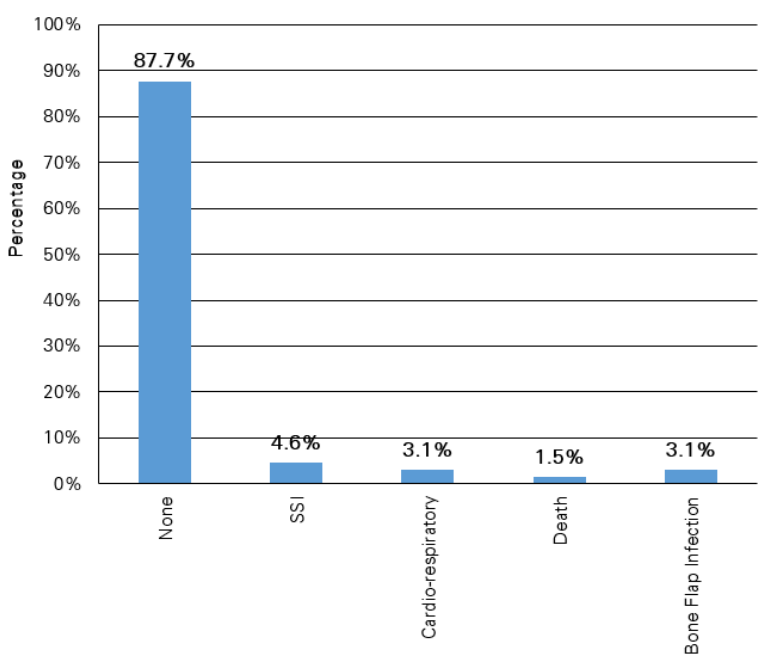

Fig 1. Bar diagram showing postoperative complications

were not any complications, 3(4.6\%) had Surgical Site Infection, 2(3.1\%) had Cardio-Respiratory complications, $2(3.1 \%)$ had bone flap infection and there was $1(1.5 \%)$ mortality as in figure 3 .

More than half of the study population $(n=33$, $50.8 \%$ ) was discharged within 4-7 days. Only $10(15.4 \%)$ had a hospital stay of more than 10 days. The other 21(32.3\%) had 8-10 days of hospital stay, and $1(1.5 \%)$ patient was discharged after 3 days of hospital stay.

Outcome analysis was assessed as per the GOS as dichotomized in two groups as unfavorable (GOS $\leq 3$ ) and favorable $(G O S \geq 4)$. One patient expired due to non-surgical complications. There was unfavorable GOS in $6.2 \%(n=4)$. Favorable outcome was seen in $92.28 \%(n=60)$ at the time of discharge. At 4 and 12 weeks follow up $93.81 \%(n=61)$ and $95.35 \%$ $(n=62)$ had favorable outcome. This suggests that the outcome of pediatric head injury is excellent when taken care of on time.

\section{DISCUSSION}

Typical features of the pediatric skull and brain account for their outcome is different than in adults like the pliability of the immature skull of a newborn makes the brain more vulnerable to injury; the lack of adequate subarachnoid space reduces its buffering capacity for externally applied impact. ${ }^{12}$ Pediatric $\mathrm{TBI}$ is a major challenge for a tertiary care center in developing countries like ours. It has always been a burden for developing countries as compared to the developed part of the world, where there is the dawn of highly specialized Intensive Care Units and a high level of multidisciplinary approach, which improves outcomes dramatically. ${ }^{13}$

Though the age as a predictor of outcome has been debated, Luersson et al. and Braakman et al. have reported age as the strongest factor for mortality 
Table 2. Correlation between pupillary reaction and GOS at discharge

\begin{tabular}{|c|c|c|c|c|c|c|}
\hline \multirow{2}{*}{ Pupils } & \multirow{2}{*}{$\begin{array}{l}\text { Count for } \\
\text { GOS }\end{array}$} & \multicolumn{4}{|c|}{ Glasgow Outcome Score } & \multirow{2}{*}{ Total } \\
\hline & & 1 & 3 & 4 & 5 & \\
\hline Both reactive & $\begin{array}{l}\text { At discharge } \\
\text { At } 4 \text { weeks } \\
\text { At } 12 \text { weeks }\end{array}$ & $\begin{array}{l}0(0 \%) \\
0(0 \%) \\
0(0 \%)\end{array}$ & $\begin{array}{c}1(25 \%) \\
1(33.3 \%) \\
0(0 \%)\end{array}$ & $\begin{array}{l}8(66.7 \%) \\
3(42.9 \%) \\
1(33.3 \%)\end{array}$ & $\begin{array}{l}42(87.5 \%) \\
47(87.0 \%) \\
50(84.7 \%)\end{array}$ & $51(78.5 \%)$ \\
\hline One reactive and one non-reactive & $\begin{array}{l}\text { At discharge } \\
\text { At } 4 \text { weeks } \\
\text { At } 12 \text { weeks }\end{array}$ & $\begin{array}{l}1(100 \%) \\
1(100 \%) \\
1(100 \%)\end{array}$ & $\begin{array}{c}2(50 \%) \\
1(33.3 \%) \\
1(50 \%)\end{array}$ & $\begin{array}{l}4(33.3 \%) \\
4(57.1 \%) \\
2(66.7 \%)\end{array}$ & $\begin{array}{c}6(12.5 \%) \\
7(13 \%) \\
9(15.3 \%)\end{array}$ & $13(20 \%)$ \\
\hline Both nonreactive & $\begin{array}{l}\text { At discharge } \\
\text { At } 4 \text { weeks } \\
\text { At } 12 \text { weeks }\end{array}$ & $\begin{array}{l}0(0 \%) \\
0(0 \%) \\
0(0 \%)\end{array}$ & $\begin{array}{c}1(25 \%) \\
1(33.3 \%) \\
1(50 \%)\end{array}$ & $\begin{array}{l}0(0 \%) \\
0(0 \%) \\
0(0 \%)\end{array}$ & $\begin{array}{l}0(0 \%) \\
0(0 \%) \\
0(0 \%)\end{array}$ & $1(1.5 \%)$ \\
\hline & Total & 3 & 4 & 12 & 48 & 65 \\
\hline
\end{tabular}

and morbidity. 10,14 In our study $61.5 \%$ head injury was sustained in those 10-16 years of age-group followed by $23.1 \%$ in $5-<10$ years, $13.8 \%$ in $2-<5$ years and $1.5 \%$ was below 2 years. The similarity in the age group was noted in the study done by Suresh et al. , where the maximum numbers of children were in 11-15 years. ${ }^{15}$

In this study, the incidence of head injury in male $43(66.2 \%)$ was more than in female $22(33.8 \%)$. Similar population distribution was found in a study done by Agrawal $\mathrm{A}$ et al and Bhargava $\mathrm{P}$ et al. ${ }^{16}$ Chiaretti et al. hypothesized that the higher incidence of TBI in boys might be due to larger head circumference, more muscular and physical activities in comparison to girls. ${ }^{17}$ In our study home and school environment was the most common place of injury to occur, Adesunkanmi et al., Kirsch et al. and Mariam et al. also showed similar findings. ${ }^{18}$

Fall $34(52.3 \%)$ were the leading cause of pediatric head injuries in all age groups followed by RTA $28(43.1 \%)$. This is supported by many other studies round the globe conducted at different centers like Gururaj et al., Jennett et al., Atabaki et al., and Vinayak $R$ et al. ${ }^{19}$ Mishra $B$ et al. performed a study showing a trend of RTA injuries in children of Nepal. ${ }^{20}$ In a study performed by Ong et al. slipping and fall from the bed were the most common causes of falls leading to pediatric head injury. ${ }^{21}$

Vomiting was the most common clinical presentation seen in $28(43.1 \%)$, followed by loss of consciousness in $18(27.6 \%)$, headache in $9(13.9 \%)$, ENT bleeds in $5(7.6 \%)$, focal neurological deficits (FND) in 3(4.6\%) and seizure in 2(3.1\%). Depressed skull fracture with contusion was the most common diagnosis seen in $27(41.52 \%)$ cases followed by $\mathrm{EDH}$ in $17(26.1 \%), \mathrm{SDH}$ in $11(17 \%)$, Contusion only in $5(7.69 \%)$ and degloved scalp in $5(7.69 \%)$. Kraus et al. 22 reported concussion (70\%) to be the most common injury in children. Similar findings were reported by Mac Gregor et al. ${ }^{23}$ Suresh et al. ${ }^{15}$ and William H. et al. ${ }^{24}$
The extent of a skull fracture is proportional to the severity of brain injury, which does not apply to the pediatric age group. ${ }^{25}$ The probability of associated intracranial hematoma with a skull fracture in children is half of that of adults. ${ }^{26} \mathrm{SDH}$ is seen six times more often in infants than in toddlers. ${ }^{25}$ However, the present study showed that $\mathrm{SDH}$ was about one-sixth of the total cases in this population. The outcome of patients with SDH is significantly worse than that of patients with EDH, mainly because of the underlying brain damage accompanying SDH and the resultant intracranial rise in pressure according to Malik NK et al. ${ }^{27}$

Many a time head injury is associated with other injuries. In our series majority, 76.9\% had no associated injuries whereas minorities had associated injuries in terms of Maxillofacial 6.2\%, Orthopedic $4.6 \%$, Thoracic $1.5 \%$, BAT $4.6 \%$, Multiple injuries $3.1 \%$ and $3.1 \%$ had spinal injuries. ${ }^{28}$

Those with poor GCS had delayed recovery and had a longer duration of hospital stay. Overall the Glasgow outcome scale was favorable in about $95.35 \%$ at 12 weeks follow-up. There was only one mortality of $1(1.5 \%)$ in the postoperative period due to severe pneumonia. Minor postoperative complications were seen but were taken care of during hospital stay. Those were minor superficial surgical site infections.

Regarding pupillary response, Suresh et al. ${ }^{15}$ reported poor outcomes in $49.3 \%$ of patients with abnormal pupils and $7.4 \%$ in normal pupils. Jennett et al. ${ }^{11}$ reported a poor outcome of $96 \%$ in fixed dilated and $50 \%$ in normal pupils. Francel et al. ${ }^{25}$ stated that papillary response is not a good predictor of outcome. In our series, we found abnormal pupillary response being the strongest predictor of outcome; $78.5 \%$ had both reactive pupils, $20 \%$ had one reactive and one non-reactive and $1.5 \%$ had both non-reactive pupils. Astrand et al ${ }^{29}$ reported $100 \%$ poor outcome in dilated pupils unresponsive to light. Considering infants 
and young children, young children suffer greater damage from diffuse cerebral edema than their older counterparts and show significant impairment in cognitive and performance skills due to injury to developing brain. ${ }^{16}$

\section{CONCLUSION}

Pediatric TBI is a concerning issue to all; in a developing society as ours, not only the prevention of secondary brain injuries is important but the treatment of primary brain injury is of key importance. This study concludes that pupillary reaction and the presenting GCS dominates the predictors for short term outcomes in the pediatric TBI. Hence, the timely management and awareness for the prevention of pediatric TBI are to be the goal for all in a developing society like ours.

\section{CONFLICT OF INTEREST}

None declared.

\section{REFERENCES}

1. Chen, W., Qi, J., and Feng, F., et al., 2014. Neuroprotective effect of allicin against traumatic brain injury via Akt/endothelial nitric oxide synthase pathway-mediated anti-inflammatory and anti-oxidative activities. Neurochem. Int. 68, 28-37.

2. Johnston $B D$, Ebel BE. Child injury control: trends, themes, and controversies. Acad Pediatr. 2013 Nov-Dec;13(6):499-507.

3. Teasdale G, Jennett B. Assessment of coma and impaired consciousness. A practical scale. Lancet. 1974; 2:81-4.

4. Su F, Raghupathi R, Huh JW. Neurointensive care for traumatic brain injury in children. eMedicine Journal. 2004; 5:1-9.

5. Dewan, MC., Mummareddy, N., Wellons, JC 3rd, et al. Epidemiology of global pediatric traumatic brain injury: qualitative Review. World Neurosurg 2016 July; 91: 497-509.e1.

6. Adirim $T A$, Wright $J$, and Lee $E$, et al. Injury surveillance in a pediatric emergency department. Am J Emerg Med. 1999; 17:499503.

7. Central Bureau of Statistics, Government of Nepal. National population report 2017

8. Chevignard M, Francillette L, Toure $H$, et al. Academic outcome, participation and health-related quality of life following childhood severe traumatic brain injury: results of a prospective longitudinal study: the seven-year follow-up of the TGE cohort. Ann. Phys. Rehabil. Med 2016; 59: e133.

9. Trenchs V, Curcoy Al, Castillo M, et al. Minor head trauma and linear skull fracture in infants: Cranial ultrasound or computed tomography? Eur J Emerg Med. 2009; 16:150-2.

10. Braakman R, Gelpke GJ, Habbema JD, et al. Systematic selection of prognostic features in patients with a severe head injury. Neurosurg. 1980; 6:362-70.

11. Jennett $B$, Teasdale $G$, Braakman $R$, et al. Prognosis of patients with a severe head injury. Neurosurg. 1979; 4:283-9.

12. Kalsbeek WD, McLauren RL, Harris BSH. The national head and spinal cord injury survey: major findings. J Neurosurg 1980;53: S19-31.

13. Wani AA, Ramzan AU, Tariq R, et al. Head injury in children due to the cricket ball scenario in developing countries. Pediatr Neurosurg. 2008; 44:204-7.

14. Luersson T, Klauber M, Marshall L. Outcome from head injury related to patients age, a longitudinal prospective study of adults and pediatric head injury. J Neurosurg. 1988; 68:409-16.

15. Suresh HS, Praharaj SS, et al, Prognosis in children with head injury; an analysis of 340 patients; J. Neurol India; 2003; 51: 16-18.

16. Agrawal A, Agrawal CS, Kumar A, et al. Epidemiology and management of paediatric head injury in eastern Nepal. Afr J Paediatr Surg. 2008 Jan-Jun; 5 (1): 15-18.

17. Chiaretti A, De Benedictis $R$, Della Corte $F$, et al. The impact of initial management on the outcome of children with severe head injury. Childs NervSyst 2002; 18:54-60.

18. Adesunkanmi AR, Oginni LM, Oyelami AO, et al Epidemiology of childhood injury.J Trauma 1998:44:506-12.

19. Gururaj G. et al; Epidemiology of traumatic brain injuries; Indian scenario; J Neurol Res; 2002, Vol 24, January: 24-28

20. Mishra B, Sinha ND, Sukhla SK, Sinha AK. Epidemiological study of road traffic accident cases from Western Nepal. Indian J Community Med 2010; 35:115-21.

21. Ong ME, Ooi SB, Manning PG. A review of 2,517 childhood injuries seen in Singapore emergency department in 1999- mechanism and injury prevention suggestions. Singapore Med J 2003; 44:12-9.

22. Kraus Jess F, Fife Daniel, Conroy Carol; Pediatric brain injuries: The nature, clinical course, and early outcomes in a defined united states' population. Pediatrics1987; 79; 501-507.

23. Macgregor D M. Injuries associated with falls from beds. Inj. Prev 2000; 6:291-292.

24. Hollingworth William, Vavilala Monica; The use of repeated head computed tomography in pediatric blunt head trauma; Factors predicting new and worsening brain injury; J. Pediatr crit Care Med; 2007 Vol.8, No.4; 348-356.

25. Francel PC, Park TS, Shaffrey ME, Youmans J, editors. Neurological Surgery. Philadelphia: WB Saunders Company; 1996. Diagnosis and treatment of moderate and severe head injury in infants and children; pp. 1730-66.

26. Teasdale GM, Murray G, Anderson E, et al. Risks of acute traumatic intracranial haematoma in children and adults: Implications for managing head injuries. BMJ. 1990; 300:363-7.

27. Malik, Makhdoomi R, et al.; Posterior fossa extradural hematoma: our experience and review of the literature; I Surgical Neurology; 2007 Aug; 68(2): 155-8.

28. Jagannathan J, Okonkwo DO, Yeoh HK, et al. Long-term outcomes and prognostic factors in pediatric patients with severe traumatic brain injury and elevated intracranial pressure. I Neurosurg Paediatr. 2008; 2:237-9.

29. Astrand R, Undén J, Hesselgard K, et al. Clinical factors associated with intracranial complications after pediatric traumatic head injury: An observational study of children submitted to a neurosurgical referral unit. Pediatr Neurosurg. 2010; 46:101-9 